\title{
La piedad filial en La Celestina: una interpretación desde la perspectiva del confucianismo
}

\author{
Lucas Sánchez Sagrado \\ Universidad de Salamanca
}

\section{RESUMEN}

Las relaciones entre padres e hijos son uno de los aspectos centrales que articulan gran parte de los acontecimientos en la obra de Fernando de Rojas. La importancia de estas relaciones no era en absoluto exclusiva a la sociedad española. El confucianismo cuenta con un término propio para designar estas relaciones, xiào (孝), traducido habitualmente como piedad filial, el cual se considera uno de los pilares básicos de sus enseñanzas y tradiciones. Aunque las relaciones paternofiliales en La Celestina han sido ampliamente estudiadas desde diversos enfoques, la interpretación de estas desde el punto de vista de la ética de las sociedades de Asia oriental es un aspecto poco estudiado. El objetivo de este artículo es analizar diversos aspectos de la dinámica de estas relaciones en la obra con el apoyo de los puntos de vista de varios autores, estudiar esas relaciones y compararlas con los preceptos establecidos en los textos clásicos del confucianismo.

Palabras Clave: Celestina, confucianismo, piedad filial.

\section{Filial piety in Celestina: an interpretation from the perspective of Confucianism}

\section{ABSTRACT}

Parent-child relationships are one of the core points which frame many of the events in Fernando de Rojas' work. The importance of these relationships wasn't at all exclusive to Spanish society. Confucianist belief possesses a word which describes these relationships, xiào (孝), usually translated as filial piety, that is one of its teachings and traditions' more important aspects. Although parent-child relationships in Celestina have been widely studied from several standpoints, the interpretation of these from the perspective of East Asian social ethics remains largely unstudied. The goal of this article is to analyze several aspects of those relationships in the work through the viewpoints of several authors, study them and compare them with the prescripts set in classical Confucian texts.

KeY words: Celestina, Confucianism, filial piety. 


\section{1.- Estado de la cuestión}

A mi modo de ver, aunque se ha trabajado en comparar La Celestina con otras obras en las que pueda estar presente este concepto, no se ha prestado suficiente atención a la posibilidad de una interpretación de la obra de Rojas en general, en sí misma, desde el prisma del confucianismo. En su artículo "Reseña y análisis del estudio comparativo entre La Celestina e Historia del ala oeste» ${ }^{`}$ Yang Xiao revisa estudios comparativos anteriores sobre estas dos obras, y señala algunos aspectos confucianos de la obra china, pero sin detenerse particularmente en la piedad filial ni trazar comparaciones al respecto con La Celestina. Lo mismo ocurre con el trabajo de Wang Zhenna Una comparación de las prostitutas en La Celestina y Du Shiniang ${ }^{2}$. Por su parte, sobre el suicidio de Melibea, Borao (2008) arguye que

momentos antes de que se quite la vida tirándose de la torre, describe algunos de sus elementos constitutivos de la piedad filial al señalar los problemas que va a causar a su padre con su decisión: [...]. En esa frase se encierran tres preceptos de la piedad filial: (b) «No dañar el honor, la honra, la fama y el buen nombre de los padres», (c) «No provocar cargas a los padres» y (d) «No abandonar a los padres en la vejez». (pp. 90-91)

Sin embargo, no justifica estas afirmaciones con las ideas confucianas propias de la dinastía Ming que por otra parte sí estudia en su artículo. Otros autores sí han tratado más específicamente la piedad filial, pero desde un punto de vista generalmente occidental.

\section{2.- Influencias para Rojas sobre la piedad filial}

Como se ha dicho, la noción de piedad hacia los padres no era precisamente desconocida para la sociedad de la época, y estaba presente en preceptos tan evidentes como el cuarto mandamiento cristiano. Obras como las Coplas a la muerte de su padre de Manrique posiblemente influyeron también en la visión social de este concepto. Pero la influencia clásica se hace presente ya en los versos acrósticos en los que Rojas justifica su continuación de la obra, con la alusión a Dédalo, probablemente tomada del Laberinto de Fortuna (Lobera et al. 2011, 12). Sin duda el mito de Dédalo e Ícaro ilustraba para las gentes de la Edad Media las consecuencias de rebelarse contra las estructuras de la autoridad paterna heredadas desde el pasado (Burke 2002).

1.- Publicado en eHumanista: Journal of Iberian Studies 35 (2017), pp-277-295.

2.- Disponible en <https://hdl.handle.net/2072/83502>. 
Otra influencia importante son las descripciones de las relaciones de padres e hijos en ciertos animales, tomadas de los bestiarios de la época, como la descripción de la víbora que asesina al macho para morir después en el parto, que ilustra la idea de la vida como conflicto en el prólogo de la Tragicomedia. También Celestina, en su primera conversación con Melibea, alude a imágenes del pelícano, que se decía que tras matar a sus crías se hería el pecho con el pico y las revivía con su sangre, y moría él después. Era utilizado en la época como figura de la piedad de Cristo, pero la finalidad burlesca es evidente al subvertir Celestina esos valores y aplicarlos a su intención de obtener una prenda de Melibea para que esta abra figuradamente el pecho y el corazón de Calisto (Raposo 2012, 278-280). Celestina hace referencia también a las cigüeñas, que se creía que cuidaban de sus padres ancianos como estos lo hicieron cuando ellas eran crías.

\section{3.- El papel de Celestina como «madre» en su relación con Pármeno, Areúsa y Elicia}

Celestina aparece en la obra como figura central que conecta a personajes de diversa clase social, a los que incluye en la categoría de "hijos» suyos, al igual que ocurría con la madre de Pármeno, su mentora - "si saliemos por la calle, cuantos topábamos eran sus ahijados» (p. 179) ${ }^{3}$. Según Cuesta (1999),

Celestina es saludada como madre [...] por Calisto, Melibea, Sempronio, Pármeno, Lucrecia, Elicia y Areúsa. Estos también reciben el nombre de hijos por parte de la alcahueta [...] Pero quien con más justa causa llama madre a Celestina es Pármeno, que siendo niño fue dado por su auténtica madre a la alcahueta como servidor. (p. 24)

En efecto, son múltiples las ocasiones en que Celestina trata de reafirmar su figura como madre de Pármeno, al que «tenía por hijo a lo menos cuasi adotivo, y así que imitaras a natural» (p. 173), como cuando le espeta:

la esperiencia no puede ser más que en los viejos. Y los ancianos somos llamados padres, y los buenos padres bien aconsejan a sus hijos, y especial yo a ti, cuya vida y honra más que la mía deseo. Y ¿̇cuándo me pagarás tú esto? Nunca, pues a los padres y a los maestros no puede ser hecho servicio igualmente. (pp. 78-79) 
Tras lo cual él piensa: «oído he que debe hombre a sus mayores creer» (pp. 78-79), y parece ceder ante ella. La vieja también le recrimina el sufrimiento que causó a sus padres biológicos por dejar la vida estable que tenía asegurada bajo su cuidado: "con otra ansia no murió sino con la incertedumbre de tu vida y persona, por la cual ausencia algunos años de su vejez sufrió angustiosa y cuidosa vida» (p. 71). Celestina utiliza un tono duro con Pármeno cuando este muestra dudas sobre ella, y le intimida con la posibilidad de que pierda los posibles beneficios que obtendría de ella, no solo carnales y materiales, sino el amor que puede ofrecerle como madre (Hawking 1967, 183). Pármeno se encuentra en una posición difícil respecto a ella, ya que a todos los efectos Celestina parece, en verdad, tan digna de ser su madre como lo fue Claudina: atendió su parto y cumplió las mismas funciones que su madre durante mucho tiempo. Tras la muerte de su madre biológica, no puede evitar transferir los sentimientos que tenía hacia ella a la otra madre que le queda cuando tiene la oportunidad (Hawking 1967, 184).

Pármeno se avergüenza de las fechorías de Claudina y quiere olvidar a esta y tomar a Celestina como nueva madre, a pesar de ser consciente de que sus formas de proceder son idénticas. Cuando Celestina se regodea en la actitud de ambas, se siente defraudado al comprender la verdad, y enfadado por el hecho de tener que cargar con la herencia criminal (Hawking 1967, 187) de sus «madres». Encontramos unas circunstancias similares en el Lazarillo de Tormes, en la responsabilidad que Lázaro siente, hacia su madre y él mismo, de conseguir una vida estable que rectifique la infamia de las acciones de su padre. Irónicamente, la propia Celestina le aconseja que procure ser bueno, de forma casi idéntica a como lo hará la madre de Lázaro (Lobera et al. 2011, 172).

La actitud de Celestina provoca las reticencias de Pármeno a la hora de confiar en ella. Al inicio de la obra, se muestra en principio leal a Calisto, a diferencia de Sempronio, y teme que la presencia de Celestina amenace la vida que trata de construir como su sirviente. Sin embargo, y a pesar de supuestamente valorar sus consejos y preocuparse por ellos, Calisto le trata con desdén y en cambio regala bienes a la alcahueta (GalarretaAima 2011, 51). Para el confucianismo, las relaciones entre hijos y padres eran extensibles a las que se daban entre súbditos y gobernantes, como se detalla en el Clásico de piedad filial: "the affection between a father and a son is natural, and also a source from which springs the reverence [...] ought to show to his sovereign. [...] We must treat our parents with the same reverence as is shown to our sovereign" (Chên 1908, 24). Además, Confucio no defendía la piedad filial como obediencia ciega, sino que insistía en que, si los padres se comportaban de forma no recta, era responsabilidad de los hijos resistir sus órdenes y tratar de corregir su actitud (Chên 1908, 29). Huang (2017) resume este concepto con su afirmación de que: 
when parents are doing moral things, a filial child should of course be obedient to them; and a filial child should also be obedient to them when they are doings things that are more or less morally neutral, even though such matter could be done more efficiently or otherwise better. However, when parents are doing immoral things a filial child, being filial, ought to remonstrate with them. (p. 28)

En la China imperial, algunos oficiales ponían incluso en riesgo sus vidas al objetar sobre las acciones de sus gobernantes, como apuntan Andrew y LaFleur (2014):

the phrase 'risking one's life in remonstrance' (jiansi; 諫 死) is particularly useful, precisely because it indicates the commitment some scholar-officials were willing to make in order to fulfill their Confucian duty to the ruler. They were willing to die for their principles. The threat of reprisals from vengeful rulers was a very real horror in the Ming dynasty (1368-1644 CE). Nevertheless, courageous officials still came forward to offer remonstrance. (p. 7)

Por lo tanto, la insistencia de Pármeno en aconsejar a su señor y en no seguir ciegamente a su "madre» sería considerada virtuosa. Pero el criado termina por rendirse: las Analectas recogen una frase que bien podría haber salido de boca de Calisto, sobre la facilidad con la que Pármeno le vuelve la espalda: «los criados son las personas de más difícil trato: si se los trata con confianza se hacen atrevidos, pero se disgustan si se les trata con desapego» (Confucio 1999, 221).

Podría decirse que el factor decisivo para vencer la resistencia del sirviente y que aparentemente prometa lealtad a Celestina es el hecho de que esta facilite su encuentro carnal con Areúsa, lo cual intenta esgrimir inútilmente cuando los criados se enfrentan a ella y la matan. En su desesperación, Pármeno le promete incluso hacerse amigo de Sempronio, algo que antes no se planteaba. En las Analectas se encuentra esta sentencia que podría aplicarse al hecho de que se entregue a ella sin seguir intentando corregir la actitud de la vieja: "iqué desgracia! No he visto a nadie que anteponga la virtud al sexo" (Confucio 1999, 193). Como opina Lacarra (2001), «la persuasión que unos personajes ejercen sobre otros sirve para señalar que existen alternativas y mostrar el libre albedrío de sus acciones. El hecho de que yerren, por tanto, no implica compulsión, sino falta de virtud» (p. 472).

Sin embargo, Pármeno no llega nunca a confiar plenamente en su nueva madre. Resulta interesante la distinta actitud de los criados en el momento de la muerte de Celestina. En principio Sempronio parece llevar la iniciativa y actúa rápidamente, más motivado por un móvil econó- 
mico y habiéndole recordado a Pármeno que deben reclamar su parte (Hawking 1967, 189), pero Pármeno entra violentamente en acción cuando Celestina insiste, en una situación cuya gravedad por una vez no es capaz de valorar, en mofarse de él al recordarle a su madre biológica - "ino me hinches las narices con esas memorias, si no, enviarte he con nuevas a ella, donde mejor te puedas quejar!» (p. 259). La codicia también mueve a Pármeno, pero no exclusivamente. Según Lida (1962) el despecho acumulado al echarle en cara la infamia de Claudina le lleva a incitar a Sempronio a que la remate - "idale, dale, acábala, pues comenzaste, que nos sentirán! ¡Muera, muera! ¡De los enemigos, los menos!» (p. 261).

Respecto a Elicia y Areúsa, una parte importante de los pasajes más significativos sobre su relación con Celestina se encuentra en los cinco actos añadidos en la Tragicomedia (el Tratado de Centurio), lo cual plantea ciertos problemas de interpretación debido a las inconsistencias de estos dos personajes entre la Comedia y la Tragicomedia, respecto a lo cual se han propuesto diversas hipótesis, como la de Lida (1962) sobre la autoría compartida entre varios autores de los actos añadidos y la posibilidad de que alguno de ellos confundiera los nombres de las muchachas, en cuyo caso la Areúsa de la Comedia sería la Elicia de la Tragicomedia, y viceversa. Puesto que esa discusión está fuera del ámbito de este trabajo, nos referiremos a ellas con los nombres con que aparecen en cada momento en la obra, independientemente del acto.

En la Comedia, Areúsa aparece, por lo general, como más sumisa ante Celestina que Elicia, a pesar de que pudiera parecer que la alcahueta tiene menos influencia sobre ella, que vive sola y prefiere ejercer su oficio con cierta clandestinidad, que sobre Elicia — «Elicia, criada y adiestrada por Celestina y lógica sucesora de esta, puede considerarse digna hija suya» (Cuesta 1999, 24); «imuerta es mi madre y mi bien todo!» (p. 261). En contraste con Elicia, que le recrimina su falta de memoria en presencia de su amante - a lo cual responde Celestina de forma tajante: «no me castigues, por Dios, a mi vejez; no me maltrates, Elicia. No enfinjas porque está aquí Sempronio, ni te soberbezcas» (p. 107)—, Areúsa le pide perdón por su reticencia inicial a acostarse con Pármeno (algo que hace también el mismo Pármeno cuando decide que es mejor obedecer a la vieja) y acepta a pesar de no obtener beneficios de ello comparables con los de Celestina. La forma en que las muchachas sobrellevan el luto por la muerte de su «madre» es muy diferente. Elicia está devastada y lo lleva rigurosamente:

si no pesase más a aquella que desde esta ventana yo veo ir por la calle, no llevaría las tocas de tal color. [...] aquella lutosa que se limpia agora las lágrimas de los ojos: aquélla es Elicia, [...] queda agora perdida la pecadora porque tenía a Celestina por madre. (p. 283) 
Areúsa queda impactada al recibir las noticias de boca de Elicia, pero se repone rápidamente para tomar una actitud más práctica al respecto, y piensa en qué beneficios se pueden obtener de la circunstancia: "pues ya esta desdicha es acaecida, pues ya no se pueden por lágrimas comprar ni restaurar sus vidas, no te fatigues tú tanto» (p. 289), "calla, por Dios, hermana, pon silencio a tus quejas, ataja tus lágrimas, limpia tus ojos. Torna sobre tu vida, que cuando una puerta se cierra, otra suele abrir la fortuna» (p. 290), "y tú, Elicia, [...] con nuevo amor olvidarás los viejos» (p. 291). Según Hawking (1967) esta actitud demuestra su similitud de carácter con la difunta, ya que advierte a Elicia de que el mantener sus ropas y actitud de luto es perjudicial para el negocio.

Su prima sigue su consejo y «entre demostrar su pena por la muerte de su protectora [...] y continuar su vida licenciosa, Elicia prefiere concluir con su corto luto» (Galarreta-Aima 2011, 56). Al comprobar su cambio de actitud, Areúsa se siente satisfecha, y llega incluso a asegurarle ya abiertamente que la muerte de Celestina puede ser beneficiosa para ella:

entra, hermana mía, véate Dios, que tanto placer me haces en venir como vienes, mudado el hábito de tristeza. Agora nos gozaremos juntas, agora te visitaré. Vernos hemos en mi casa y en la tuya; quizá por bien fue para entramas la muerte de Celestina, que yo ya siento la mejoría que antes. Por esto se dice que los muertos abren los ojos de los que viven, a unos con haciendas, a otros con libertad, como a ti. (p. 301)

En el confucianismo, el luto por los padres debía durar tres años, y era considerado de tal importancia que incluso el emperador lo seguía, como se recoge en las Analectas:

el Libro de la historia [...] afirma que el emperador Gao Zong no habló durante los tres años perceptivos de luto [...] Todos los hombres de la antigüedad hacían lo mismo. Cuando un soberano moría, los diferentes funcionarios tomaban las órdenes para atender a sus obligaciones de boca del primer ministro durante los tres años en que el nuevo soberano guardaba luto... (Confucio 1999, 186)

Era importante expresar la tristeza durante ese periodo, pero debía procurarse volver a la vida normal tras este: «en caso de luto, se debe llegar hasta el último extremo del dolor, pero hay que detenerse allí» (Confucio 1999, 235), aunque después se ofrecían ritos a los padres regularmente. También era importante cuidarse a sí mismo en la medida de lo posible, ya que el Clásico de piedad filial afirma que el pelo, la piel, y en definitiva, todo el cuerpo, eran una herencia de los padres que no debía ser dañada bajo 
ningún concepto (Chên 1908, 16). Por ello el Clásico recalcaba la importancia de comer, aunque no se tuviera apetito, y reiteraba que los tres años no debían sobrepasarse, pues marcan el límite del dolor (Chên 1908, 32). De igual forma, acortar la duración del duelo no era una opción:

Zăi Wǒ preguntó a Confucio si bastaría con un año de luto en lugar de tres. [...] Confucio le preguntó [...]: '¿Te sentirías contento comiendo buenas cosas y llevando vestidos bordados después de transcurrido sólo un año? [...] un hombre superior no disfruta ni del dulce que come ni de la música que oye mientras dura el luto y tampoco se siente a gusto en el lugar en que habita. [...] un niño no se separa del regazo de sus padres hasta que no han pasado tres años desde su nacimiento, por eso los tres años de luto se guardan en todo el mundo. ¿Acaso Zăi Wǒ no disfrutó de aquellos tres años de amor que le dieron sus padres?' (Confucio 1999, 220)

Esta obligación se extendía también a los oficiales civiles y militares del gobierno, que debían abandonar sus puestos durante el periodo de luto. A menudo debían enfrentarse, debido a ello, a una disyuntiva equivalente a la de Elicia, pues ese periodo de inactividad profesional podía tener un impacto negativo en su carrera. Sin embargo, el no cumplirlo, a menos que se tratase de un oficial de alto rango que fuera llamado por el gobierno por la importancia de su puesto, podía acarrear graves consecuencias. Hamilton (1990) apunta que

the T'ang codes specified several areas of filial infractions. [...] Unfilial behaviour (pu-hsiao) [...] was [...] ceasing to observe mourning before the end of the required mourning period [...] (Ch'u, ibid., p. 26). [...] infractions against one's parents [...] fell in a broad category called 'disobeying instructions'. Exile and beating with heavy and light sticks were posible punishments [...] (pp. 102-103)

De las peculiaridades estudiadas acerca de las relaciones «madre-hijos» de Celestina con Pármeno y las muchachas se puede extraer la conclusión de que son, en rasgos generales, motivadas por el interés, algo que será aplicable también al caso de Melibea. Según Alcalá (1996),

su maternidad postiza, el ser llamada "madre» por todos, se basa en un acuerdo tácito de aparentar $-\mathrm{y}$ autoconvencerse- de la bondad y espontaneidad de sus relaciones con los demás, que siempre llevan el sello de lo ilícito. $\mathrm{Su}$ «maternidad» está asimismo caracterizada 
por la debilidad afectiva en ambas direcciones, tanto por parte de la madre como por parte de sus «hijos» que ven en la vieja un medio para conseguir fines deseados, fines independientes de ella como persona. (p. 40)

De igual modo, la alcahueta está dispuesta a comerciar con favores sexuales, la lealtad de los sirvientes, piedad filial, afecto de madre, caridad cristiana, amistad, y amor (Gaylord 1991, 2). Cuando Sempronio y Pármeno la visitan a altas horas de la madrugada con el propósito de reclamar su parte de la recompensa, llaman y le dicen que abra a sus hijos, a lo que ella responde: «no tengo yo hijos que anden a tal hora» (p. 254), algo que ella misma suele hacer - "¿cómo vienes tan tarde? No lo debes hacer, que eres vieja; tropezarás donde caigas y mueras» (p. 237); "éstas son tus venidas; andar de noche es tu placer. ¿Por qué lo haces? ¿Qué larga estada fue ésta, madre? Nunca sales para volver a casa, por costumbre lo tienes» (p. 183). Una vez obtenido su pago y sin intención de compartirlo, y al intuir el motivo de la visita de los criados, Celestina no tiene interés en mantener las apariencias con sus «hijos». Para Hawking (1967), uno de sus errores fatales es no comprender que las expectativas de Pármeno van más allá de ese interés y espera también recibir amor de ella, o, si realmente comprende sus sentimientos, explotarlos para su propio beneficio.

\section{4.- Pleberio, Alisa, Celestina y Melibea}

Aunque "Melibea es el único personaje que goza de una legítima y explícita institución familiar» (Muñoz-Basols 2003, 111), el papel de sus padres, especialmente el de Alisa, es en gran medida ocupado por Celestina (Grieve 1990 citado en Lobera et al. 2011, 818-819). Lida (1962) define a Alisa como «la gran dama, soberbia de su posición social» (p. 489). La madre de Melibea ha sido dibujada en numerosas ocasiones como inocente, excesivamente confiada en su hija, y con su voluntad anulada por los poderes de Celestina. Sin embargo, en la primera visita de Celestina, antes de poder estar bajo su influencia, Alisa la deja pasar - "ya me voy recordando della. Una buena pieza; no me digas más. Algo me verná a pedir. Di que suba» (p. 116)—, a pesar de ser perfectamente consciente de quién es por su anterior vecindad. Resulta interesante al respecto la postura de Harney (1993), que plantea la posibilidad de que la figura de la alcahueta pudiera despertar la simpatía y respeto de madre e hija por su posición social, que permite a las mujeres ejercer su libertad más allá del mandato patriarcal sobre su matrimonio.

Sin embargo, "hay en la relación de Alisa con su hija un atisbo de aspereza que falta por completo en la de Pleberio. Alisa, cuando vuelve a encontrarse con Celestina, amonesta a Melibea con tono grave [...] lo que 
Pleberio nunca hace» (Lida, 1962, p. 488). En respuesta, Melibea, podría decirse que ya influida por los métodos de Celestina, miente a su madre al fingir sorpresa e ingenuidad y prometer guardarse de mantener contacto con la vieja (Lida, 1962, p. 417), y parece marcar distancias con ella a través del uso del término "señora» en vez de «madre» (Muñoz-Basols, 2003, p. 115), el cual sí suele aplicar a Celestina. A partir de ese momento Celestina es cada vez un referente materno más importante para ella en comparación con Alisa, como razona Hawking (1967): "Celestina achieves this end by posing as a mother figure, replacing Alisa as Melibea's mother, simply because she tells Melibea what she wants to hear, whereas Alisa, had she known the circumstances, would certainly not have encouraged her daughter» (p. 178). En su monólogo en el acto XX, la joven "se reprocha haber descubierto a una extraña lo que encubría a su madre» (Lida 1962, 407). Melibea parece sentir un mayor afecto por su padre, y le duele la posibilidad de afligirle por la confianza que él deposita en ella y el hecho de que no le reproche ni reprenda nada (Lida 1962, 471). En esta situación aparecen invertidos los ideales de padres de una sociedad confuciana, donde "parents are described as being [...] stern and dignified [...] in the case of an ideal father, 'gentle and compassionate' [...] in the case of an ideal mother» (Jordan 1998, 269). La relación de madre e hija se hace patente cuando Melibea rehúsa ver a Alisa en su momento de máximo dolor, aunque Pleberio «intenta persuadirla con la figura de su madre [...] a pesar de las circunstancias que han desencadenado una oposición de relación entre ambas [...] Pleberio intenta explotar semánticamente la imagen de la relación madre-hija para persuadir a Melibea» (Muñoz-Basols 2003, 119).

Tras la primera cita de los enamorados, Pleberio y Alisa se sobresaltan enormemente al escuchar ruidos en la cámara de su hija. Melibea reflexiona sobre su preocupación: "(no hay tan manso animal que con amor o temor de sus hijos no asperee. Pues ¿qué harían si mi cierta salida supiesen?)» (p. 252). La primera frase, tomada de Petrarca (Lobera et al. 2011, 901), tiene similitud con otra encontrada en las Analectas: «los padres se preocupan con la sola idea de que los hijos puedan enfermar» (Confucio 1999, 57).

La percepción de su honor y por lo tanto de sus obligaciones es muy diferente en los amantes. De acuerdo con Lida (1962) «Calisto [...] aparece solo, sin familia y sin arraigo social, en tanto que Melibea [...] se presenta dentro del marco familiar [...] preside su conducta desde su primera hasta su última aparición» (p. 406). Debido a ello, Melibea expresa en varios momentos de la obra la importancia de preservar la honra de sus padres, como en la primera conversación con Celestina - «perder y destruir la casa y honra de mi padre por ganar la de una vieja maldita como tú» (p. 127)—, o el momento en que pierde su virginidad con Calisto, donde de nuevo parece temer más las represalias por parte de Alisa que de Pleberio: 
¡oh pecadora de ti, mi madre, si de tal cosa fueses sabidora, cómo tomarías de grado tu muerte y me la darías a mí por fuerza! ¡Cómo serías cruel verdugo de tu propia sangre! ¡Cómo sería yo fin quejosa de tus días! ¡Oh mi padre honrado, cómo he dañado tu fama y dado causa y lugar a quebrantar tu casa! (p. 275)

Sobre el momento posterior en que Melibea le confiesa a su padre la pérdida de su virginidad, Lida (1962) señala que «la desnudez de sus palabras es ominosa, pues implica tan violento desacato al tabú social que prescribe la perífrasis, como sólo puede cometerse en el momento de la muerte» (p. 344). Las expectativas para una mujer en una sociedad confuciana eran similares a las que rompe Melibea: «In [...] Confucianism [...] a 'good' young girl is [...] expected to keep her virginity until she gets married and to get married only once in her life" (Pastoetter 2004, 1344).

Pleberio se lamenta en el final de la obra: "iya quedas sin tu amada heredera? ¿Para quién edifiqué torres? ¿Para quién adquirí honras? ¿Para quién planté árbores? ¿Para quién fabriqué navíos?» (p. 339), donde expresa su visión de Melibea como heredera y no como hija, en términos puramente materiales y comerciales (Dunn 1976, 414). El concepto de la honra hacia los padres era considerado también vital dentro de la piedad filial china, donde el Clásico de piedad filial subrayaba que no se debe hacer nada en el transcurso de un día que pueda causar un deshonor para los progenitores (Chên 1908, 20).

Respecto a las posibilidades de matrimonio de Melibea para preservar la estirpe de su padre, Harney (1993) indica que

Medieval European kinship [...] had [...] been character-
ized [...] by a thoroughly agnatic (i.e., patrilineal) ideolo-
gy. The essential elements of this system were [...] strict
control of the sexuality and marriage of daughters. The
typical pattern was one of [...] marrying off of daugh-
ters, through politically advantageous matchmaking [...]
or, in the case of brotherless daughters (the apparent
situation of Melibea), the recruitment of sons-in-law as
surrogate male heirs of their brides' lineage (i.e., as pro-
viders of inheriting grandchildren for that lineage), in the
pattern known as the epiclerate. (p. 34)

En cuanto a la sociedad china tradicional, Clemens (2006) apunta que la influencia confuciana establecía un patrón similar: el tipo de matrimonio predominante era el patrilocal, en el que la mujer se trasladaba a la casa de los padres del marido al casarse. Las familias preferían tener hijos varones porque perpetuaban el linaje, trabajaban y cuidaban de los padres en la vejez, mientras que las hijas producían descendencia para otra fami- 
lia. Al igual que en la sociedad española medieval, si la familia solo tenía una hija (como en el caso de Melibea) y deseaba asegurar su continuidad, el yerno podía trasladarse a la casa de esta, donde él o alguno de los hijos que tuvieran adoptaba el apellido de la familia de la mujer. Las familias que enviaban a sus hijos a vivir con sus esposas solían tener varios hijos varones y poca propiedad que estos pudieran heredar. En cualquier caso, este matrimonio matrilocal era poco frecuente debido al estigma que a menudo llevaba asociado.

Resulta de interés la afirmación de Pleberio de que "parecerá ya mejor en su propria casa que en la nuestra» (p. 294). Harney (1993) opina en este caso que

The factor that does not correspond to the epiclerate as typically practiced is the implied post-marital residence of Melibea, in the match envisioned by Pleberio. Where the epiclerate customarily involves a son-in-law taking up residence with his bride's kin [...], the Celestina conveys a notion of neolocal (involving an independent household for the married couple) or perhaps patrilocal residence (i.e., with husband's kin). The latter possibility may be preferred in the society for which the work was written, even in cases of heiresses who, like Melibea, are only children. (pp. 35-36)

Aunque el linaje de Pleberio estuviera asegurado con el matrimonio, resulta peculiar el hecho de que aparentemente prefiera que su hija forme una familia junto con la de su marido o incluso que los esposos vivan de forma independiente. En la sociedad china de la época los padres habrían sido mucho más reticentes respecto a la posibilidad de un matrimonio patrilocal en ese caso, ya que se consideraba de gran importancia la proximidad de los hijos a la casa de los padres para facilitar su cuidado en la vejez - «la piedad filial significa el ser capaz de mantener a los padres» (Confucio 1999, 57). La posibilidad de un matrimonio neolocal estaría probablemente descartada, ya que hasta la revolución comunista en China solo tuvieron relevancia los otros dos modelos.

Es importante tener en cuenta las posibilidades que tendría Melibea a la hora de elegir a un marido. Borao (2008) opina que

sólo cabe la explicación de que Melibea, aunque no se indique expresamente en la novela, sabe que sus padres esperan un partido diferente al de Calisto, por ello la contradicción que se produce entre el amor filial a sus padres y el amor por Calisto le lleva a la desesperación. (p. 90)

En contraste con esta visión de la autoridad absoluta de Pleberio, es relevante la observación de Dunn (1976) sobre el hecho de que «all perceive 
Pleberio as [...] father [...] and [...] man of privileged status: it follows that he must be jealous, vigilant, quick to draw the sword and unleash the dogs. Pleberio sees his [...] daughter as being [...] under his protection. Both suppositions are wrong» (p. 411). Su propia hija podría asumir esa imagen que no se correspondía completamente con la realidad. Pleberio plantea la posibilidad de dejarle elegir, aunque él tenga la última palabra, según la tendencia de la época — - the patrilineal system insists on establishing a taboo around the question of marital consent. From the twelfth century, we know, the Church had inculcated the notion of individual consent as the definitive factor in matrimony" (Harney 1993, 40). Según Lida (1962) «Pleberio [...] cree que los padres deben dar a escoger marido a sus hijas, Alisa protesta que con ello no se hará más que escandalizar a la inocente doncella» (p. 488). En cuanto al confucianismo, Menander (1915) sostiene que
the father of the bride was then approached by the father of the prospective bridegroom; his consent was the con- sent of his daughter. [...] she could refuse to acquiesce and a considerate father would not coerce her choice; but filial obedience and confidence were often the only ele- ments operative in determining that choice. (p. 146)

Cualquiera que fuese el sistema y el esposo que hubieran preferido los padres de Melibea, el propósito era evidente. Según Muñoz-Basols (2003) «el entorno familiar se construye como un ejemplo que pretende ser imitado por los hijos para perpetuar los valores jerárquicos de la familia", y Lacarra (2001) afirma que "Pleberio piensa en casar a Melibea al considerar la cercanía de su propia muerte y la necesidad de tener herederos que aseguren su hacienda y le permitan morir en paz» (p. 464). Pero el desenlace de la obra frustra cualquier posibilidad de continuidad de la familia de Pleberio - "Melibea's self-inflicted end guarantees an end to her father's line [...]: it quite literally signifies the Fall of the House of Pleberio» (Gerli 1997, 74).

Ese acto final y más extremo de Melibea, matarse y quedar «hecha pedazos» frente a sus padres, sería considerado un pecado de gran gravedad para la sociedad cristiana de la época, y llevaría a que, en contra de los deseos expresados en su monólogo final, no recibiera honras fúnebres a menos que se arrepintiese, cosa que no hace (Lobera et al. 2011, 331). Aunque "el suicidio como única salida honrosa de situaciones extremas es una idea elemental en el mundo romano clásico, recurrente en múltiples ejemplos históricos y literarios» (Lobera et al. 2011, 341), los suicidios de la ficción motivados por el «loco amor», como los de Dido o Tisbe y Píramo, eran considerados reprobables (Lacarra 2007, 182). La tradición cristiana mantenía la condena del suicidio ya presente en la cultura griega, donde, como precisa Loraux (1989) «la lengua griega carece de vocablo específico 
para designar el acto del suicidio, y [...] utiliza las mismas palabras que nombran el homicidio de los padres, ignominia absoluta» (p. 33).

Un acto así sería, en principio, inconcebible también para el confucianismo, puesto que entraría en conflicto con la máxima de no dañar el cuerpo recibido de los padres. Sin embargo, mientras que en la sociedad en la que se desarrolla La Celestina "a veces se relacionaba el suicidio con la vanagloria, con referencias a la iactatio, especialmente cuando los suicidas razonaban su muerte como un acto para mantener el honor o la lealtad» (Lacarra 2007, 176) y que "tanto la legislación canónica como la secular condenaban el suicidio y [...] las penas revertían en la familia, que quedaba muy perjudicada en su honor y con frecuencia también en su economía» (Lacarra 2007, 179), en las Analectas Confucio afirma que «el letrado de voluntad firme y, en general, el hombre virtuoso, no buscan conservar la vida si ello supone un daño para la virtud. Hay casos en los que la muerte física es la última perfección de la virtud cívica» (Confucio 1999, 191-192).

Esta aparente contradicción está relacionada con la necesidad de guiar a los padres hacia un comportamiento recto y virtuoso en caso de ser necesario, explicada en el epígrafe anterior. De acuerdo con esta lógica, Melibea debería haber insistido, antes de que la situación se descontrolara, en que la casasen, obligación que como padres no debían posponer. Huang (2017) considera que «if one allows one's parents to commit a wrongdoing, instead of remonstrating with them against it, one puts one's parents in an immoral situation» (p. 32). Si se da esa situación, era aceptable que un hijo cargara con la responsabilidad o el castigo por la falta de virtud de sus padres (Huang 2017, 38). Esto podía tener también el beneficio de llevar a los padres a cambiar su actitud:

the suffering of such a punishment in itself can serve the purpose of remonstrating with one's parents so that they do not commit any further wrongdoings. As all parents wish their children well, seeing them (children) punished for crimes committed by themselves (parents), they (parents) will naturally have the feelings of remorse and thus may become motivated to be better persons. (Huang 2017, 38)

Cabe señalar que la negligencia de Pleberio y Alisa no constituye un "crimen», a pesar de ser criticable según la mentalidad de la época, como afirma Lacarra (2001):

la tardanza de Pleberio en proveer marido a Melibea es inexcusable. Casar pronto a las hijas para evitar que se descarriaran era una lección en la que todos los tratados sobre la educación de las doncellas insistían y Melibea 
con sus veinte años tiene edad más que suficiente para el matrimonio. (p. 464)

Huang (2017) repasa la historia confuciana de un hijo que se suicidó de forma altruista para ser castigado por no evitar que su padre actuase mal (p. 36) y Guarde (2012) ilustra otro caso en el que

el suicidio [...] restablece la pérdida de valor moral, pues muestra, por un lado, hasta qué punto era importante su padre, y por otro, hasta dónde es capaz de sacrificarse por llevarse con él su miasma y evitar extenderla a los que le rodean. (p. 285)

Aunque estos casos solo se consideraban apropiados en situaciones extremas, en mi opinión la gravedad de la situación, al no solo no haber corregido a sus padres sino también aprovecharse de ello para dejarse llevar por sus pasiones y deseos individuales, y la imposibilidad de recuperar su honra en vida al haber perdido la virginidad -como dice Lucrecia: "no hay quien ponga virgos, que ya es muerta Celestina» (p. 295)-, podrían hacer justificable su suicidio para una sociedad confuciana, aunque para Melibea la razón principal para morir sea reencontrarse cuanto antes con Calisto. Según Lacarra (2007), para Pleberio «era preferible una hija muerta que una hija deshonrada» (p. 206), y la propia Melibea asegura: "con mi pena, con mi muerte, purgo la culpa que de su dolor se me puede poner» (p. 330).

Respecto al momento del suicidio, Cherchi (1997) sostiene que «pide a los padres que le traigan instrumentos para cantar [...] Mas Melibea no canta: la demanda se debe a la piedad filial que le impide suicidarse ante la vista de sus padres» (p. 83). A mi entender, la piedad filial no influye en esa petición, de hecho, aunque no se lance al vacío cuando ellos están a su lado, su padre la ve desde abajo y al caer queda muerta junto a sus progenitores. Simplemente es una estratagema - que recuerda a la que utiliza Dido (Lobera et al. 2011, 329)_ para conseguir que Pleberio y Lucrecia se vayan y poder cerrar la puerta de forma que nadie pueda evitar su muerte:

Melibea's suicide is symbolically portrayed as a final gesture of enclosure: "Quiero cerrar la puerta, por que ninguno suba a me estorvar mi muerte» [...], she says as she secures the door to the tower from which she leaps to her extinction. (Gerli 1997 73) 


\section{5.- Conclusiones}

En este trabajo hemos recogido y comparado las interpretaciones de diversos autores sobre el concepto de la piedad filial en la Celestina, además de aportar ideas propias sobre las posibles interpretaciones desde las ideas confucianas. En mi opinión, se puede concluir que, a pesar de las diferencias evidentes en la interpretación y la aplicación práctica de este concepto, se trata de una idea que compartían y comparten las sociedades china y española, y resulta ciertamente interesante la similitud que se puede observar entre algunos ejemplos, momentos, personajes, acciones, etc. de la obra de Rojas y otros que ilustraban para la sociedad confuciana china, de igual manera, la importancia de la piedad filial.

Bajo mi punto de vista, el estudio de la obra en relación con las diversas religiones y doctrinas propias de Asia Oriental es un campo de investigación que puede resultar fructífero, especialmente si se amplía la perspectiva hacia, por ejemplo, el budismo, el taoísmo, etc. Esa podría ser una dirección que seguir para ampliar las pinceladas trazadas en este trabajo. También puede ser relevante el estudio de ciertos aspectos tratados aquí desde el pensamiento de otras sociedades de Asia Oriental con influencias de las ideas confucianas en sus valores, pero con sus propias particularidades, por ejemplo, la muerte de Melibea según las características únicas de la concepción del suicidio en Japón o Corea del Sur. 


\section{Bibliografía}

Alcalá Galán, M. (1996). "Voluntad de poder en Celestina». Celestinesca, 20 (1-2), 37-55.

Andrew, A., y LaFleur, R. A. (2014). «Remonstrance: The Moral Imperative of the Chinese Scholar-Official». Education About Asia, 19 (2), 5-8.

Borao, J. E. (2008). «La piedad filial en algunos autores del Siglo de Oro y de la China Ming». En J. M. Usunáriz Garayoa y R. García Bourrellier (Eds.), Padres e hijos en España y el mundo hispánico: siglos XVI y XVIII. Madrid: Visor, 89-108.

Burke, J. F. (2002). "Authority and Influence-Vocation and Anxiety: The Sense of a Literary Career in the Sentimental Novel and Celestina». En P. Cheney y F. A. de Armas (eds.), European Literary Careers: The Author from Antiquity to the Renaissance. Toronto: University of Toronto Press, 129-145.

CHÊN, I. (1908). The book of filial duty, translated from the Chinese of the Hsiao Ching. Londres: John Murray.

CHerCHI, P. (1997). "Onomástica celestinesca y la tragedia del saber inútil». En R. Beltrán Llavador y J. L. Canet Vallés (Eds.), Cinco siglos de Celestina: aportaciones interpretativas. Valencia: Universitat de València, 77-90.

Clemens, M. (2006). "Changes in Post-Marital Residence Rules in an Era of National Reform: The Urban to Rural Disjunction in Contemporary China». Nebraska Anthropologist, 21, 22-40.

Confucio. (1999). Analectas. Reflexiones y enseñanzas (J. Pérez Arroyo, Trad.). Barcelona: Círculo de Lectores.

Cuesta Torre, M. L. (1999). «Los lazos familiares en La Celestina». Cuadernos del Sur: La Celestina (1499-1999) [suplemento especial por el V Centenario de la obra], (612), 24-25.

Dunn, P. N. (1976). Pleberio's World. PMLA, 91 (3), 406-419. <https://doi. org/10.2307/461691>.

Galarreta-Aima, D. (2011). «El tiempo en La Celestina: el deseo, el placer y el egoísmo como motivos de interpretación de la obra». Celestinesca, 35, 43-66.

GaYlord, M. M. (1991). «Fair of the World, Fair of the Word: The Commerce of Language in La Celestina». Revista de Estudios Hispánicos - University of Alabama, 25 (1), 1-27.

Gerli, E. M. (1997). "Precincts of Contention: Urban Places and the Ideology of Space in Celestina». Celestinesca, 21 (1-2), 65-77.

Guarde Paz, C. (2012). Virtud y consecuencia en la literatura histórica y filosófica pre-Han y Han: el dilema ético en la filosofía y sociedad china (Tesis doctoral inédita). Barcelona: Universitat de Barcelona. En línea: <http:// hdl.handle.net/2445/41708>

Hamilton, G. G. (1990). «Patriarchy, Patrimonialism, and Filial Piety: A Comparison of China and Western Europe». The British Journal of Sociology, 41 (1). En línea: <https://doi.org/10.2307/591019>. 
Harney, M. (1993). «Melibea's Mother and Celestina». Celestinesca, 17 (1), 33-46.

Hawking, J. (1967). «Madre Celestina». En G. C. Rossi (Ed.), Annuli dell'Istituto Universitario Orientale, Sezione Romanza. Nápoles: Instituto Universitario Orientale di Napoli, Vol. 2, 177-190.

Huang, Y. (2017). "Why an Upright Son Does Not Disclose His Father Stealing a Sheep: A Neglected Aspect of the Confucian Conception of Filial Piety». Asian Studies, 5 (1), 15-45. En línea: <https://doi. org/10.4312/as.2017.5.1.15-45>

Jordan, D. K. (1998). «Filial Piety in Taiwanese Popular Thought». En W. H. Slote y G. A. D. Vos (Eds.), Confucianism and the Family. Albany, NY: SUNY Press, 267-284.

LACARRA, E. (2001). "Sobre la cuestión del pesimismo y su relación con la finalidad didáctica de La Celestina». En S. López-Ríos (Ed.), Estudios sobre "La Celestina». Madrid: Istmo, 457-474.

- (2007). "La muerte irredenta de Melibea». En J. C. Conde (Ed.), Actas del Simposio Internacional 1502-2002: Five Hundred Years of Fernando de Rojas' "Tragicomedia de Calisto y Melibea» (18-19 de octubre de 2002, Departmento de Español y Portugués, Indiana University, Bloomington). Nueva York: Hispanic Seminary of Medieval Studies, 173-208.

Lida de Malkiel, M. R. (1962). La originalidad artística de "La Celestina». Buenos Aires: Editorial Universitaria de Buenos Aires.

LoRAuX, N. (1989). Maneras trágicas de matar a una mujer (R. Buenaventura, Trad.). Madrid: Visor.

Menander Dawson, M. (1915). The Ethics of Confucius. The Sayings of the Master and his Disciples upon the Conduct of the "Superior Man". Nueva York-Londres: G. P. Putnam's Sons/The Knickerbocker Press.

MuÑOz-BAsols, J. (2003). "La funcionalidad de la adopción discursiva en La Celestina: de Melibea a Melilithbea». Celestinesca, 27, 107-124.

Pastoetter, J. (2004). «Vietnam (Công Hoa Xa Hôi Chú Nghia Viêt Nam) (Socialist Republic of Vietnam)». En R. T. Francoeur y R. J. Noonan (Eds.), The Continuum Complete International Encyclopedia of Sexuality. Nueva York-Londres: The Continuum International Publishing Group, 1337-1362.

Raposo, C. I. (2012). «Bestias, amores y burlas en la literatura castellana del siglo Xv: del Cancionero a Celestina». Letras: revista de la Facultad de Filosofía y Letras de la Pontificia Universidad Católica Argentina, 65-66, 275-282. Recuperado de <http://bibliotecadigital.uca.edu.ar/repositorio/revistas/bestias-amores-burlas-literatura-castellana.pdf $>$

Rojas, F. de. (2011). La Celestina: Tragicomedia de Calisto y Melibea (Edición y estudio de Francisco J. Lobera y Guillermo Serés, Paloma Díaz-Mas, Carlos Mota, e Íñigo Ruiz Arzalluz, y Francisco Rico). Barcelona: Galaxia Gutenberg-Círculo de Lectores. 